\title{
PENGARUH PENINGKATAN KUALITAS SERAT RESAM TERHADAP KEKUATAN TARIK, FLEXURE DAN IMPACT PADA MATRIKS POLYESTER SEBAGAI BAHAN PEMBUATAN DASHBOARD MOBIL
}

\author{
Herwandi ${ }^{1^{*}}$, Robert Napitupulu ${ }^{2}$ \\ Dosen Prodi Teknik Perancangan Mekanik, Jurusan Teknik Mesin, Polman Negeri Bangka \\ Belitung ${ }^{1,2}$
}

Politeknik Manufaktur Negeri Bangka Belitung, Sungailiat, Kawasan Industri Airkantung, 33211,2) ayaxherwandi59@gmail.com ${ }^{1}$

\begin{abstract}
Abstrak
Tanaman resam (dicranopteris linearis) merupakan pakis hutan yang hidup di perkebunan karet dan tumbuh hampir diseluruh provinsi di Indonesia. Tumbuhan ini menjalar dan memiliki panjang kurang lebih 7 meter. Penelitian yang sudah dilakukan oleh peneliti lain menunjukkan bahwa penggunaan serat alam sebagai bahan komposit dapat ditingkatkan dengan $\mathrm{NaOH}$. Tujuan penelitian ini adalah untuk mendapat bahan komposit baru, hasil dari perlakuan kimia dengan larutan $\mathrm{NaOH}$ terhadap serat resam. Tahapan proses penelitian ini yaitu pembuatan sampel uji, pengujian mekanik dan analisis data. Bahan-bahan untuk pembuatan sampel diantaranya adalah serat, resin Yukalac 157 BQTN-EX, MEKPO sebagai hardener, $5 \% \mathrm{NaOH}$ dan wax glasses sebagai pencegah menempelnya resin ke cetakan. Benda uji dibuat dengan cara mencampurkan secara acak serat ke resin. Sebelumnya serat sudah dibuat tiga ukuran panjang yaitu: $20 \mathrm{~mm}, 40 \mathrm{~mm}$, dan $60 \mathrm{~mm}$. Ukuran benda uji dibuat berdasarkan standar uji tarik (ASTM D 638), uji flexure (ASTM D 790) dan uji impact (ISO-179). Nilai paling tinggi uji tarik 30,750 MPa, modulus elastisitasnya $9400 \mathrm{MPa}$. Nilai maksimum tegangan flexure $138 \mathrm{MPa}$ dan nilai paling tinggi uji impact adalah $54,14 \mathrm{~kJ} / \mathrm{m}^{2}$. Kesimpulan dari penelitian ini adalah hasil uji tarik, uji flexure dan uji impact sudah memenuhi standar plastic yang digunakan dashboard mobil.
\end{abstract}

Kata kunci: Serat Resam, Komposit, Resin, Uji Tarik,Uji Flexure, Uji Impact

\section{PENDAHULUAN}

Penggunaan serat alam (serat alam Gambar 1) selain dapat berfungsi sebagai penguat dan meningkatkan sifat mekanik polimer juga dapat mengurangi biaya produksi [1]. Dalam dekade ini, material komposit dengan penguat serat alam telah diaplikasikan oleh para produsen mobil (lihat Gambar 1). Keuntungan pemakaian komposit ini adalah memiliki sifat mekanik yang baik, tidak mudah korosif, bahan baku yang mudah diperoleh dengan harga yang lebih murah, memiliki massa jenis yang lebih rendah dibanding dengan serat mineral dan mampu berfungsi sebagai peredam suara yang baik $[2,3,4]$.

Serat alam selain memiliki banyak keuntungan, sebenarnya juga memiliki banyak kelemahannya, diantaranya adalah kekuatannya yang rendah khususnya terhadap


Gambar.1 Macam-macm serat alam dan Aplikasi serat alam dalam automotive [5]

beban kejut, kehandalannya juga rendah, mudah menyerap air, tidak tahan pada suhu tinggi, kualitasnya sangat bervariasi tergantung dari musim, umur, kondisi tanah dan lingkungan. Untuk mengatasi kelemahan tersebut, serat harus diolah terlebih dahulu. Untuk beberapa jenis tumbuhan, seperti flax, rami dan kenaf dapat dilakukan secara alami oleh mikroba. Dalam proses ini, tumbuhan direndam dalam air di ladang sekitar 2-3 
minggu tergantung dari kondisi cuaca, sehingga serat mudah dipisahkan dari pectin, yaitu bagian tumbuhan yang menghubungkan ikatan serat dengan inti kayu.

Proses selanjutnya adalah memisahkan serat dari hemicellulosa, lignin, dan sebagian kecil unsur lain dengan perlakuan alkali. Proses ini dapat meningkatkan kekasaran permukaan serat, sehingga permukaan kontaknya juga meningkat. Oleh sebab itu, perlakuan alkali dapat menyebabkan mechanical interlocking yang lebih baik [6]. Bahan kimia yang sederhana dan efektif untuk perlakuan alkali pada serat adalah $\mathrm{NaOH}$. Penentuan konsentrasi $\mathrm{NaOH}$ dan waktu perendaman yang tepat dapat menghasilkan sifat mekanik komposit yang optimal. Konsentrasi $\mathrm{NaOH}$ yang banyak digunakan oleh para periset adalah $0,5-20 \%$, sedangkan waktu perendaman berkisar 15 sampai 96 menit [7]. Seorang peneliti yang bernama Prasad menyimpulkan bahwa waktu rendam optimal adalah 72 jam dan konsentrasi $\mathrm{NaOH}$ $5 \%$ dalam aquades yang menghasilkan kekuatan tarik serat tertinggi, sedangkan waktu rendam 96 jam dan konsentrasi $\mathrm{NaOH} 5 \%$ menghasilkan modulus Young terbaik [8]. Hasil riset yang dilakukan peneliti lain yang bernama Nayak menunjukkan bahwa perlakuan kimia serat dengan konsentrasi $\mathrm{NaOH} 2 \%$ dan waktu rendam 1 jam menghasilkan kekuatan komposit tertinggi, sedangkan konsentrasi $\mathrm{NaOH} 5 \%$ dengan waktu rendam 1 jam menghasilkan sifat lentur terbaik [9].

Dalam penelitian yang sudah dilakukan terhadap komposit yang diperkuat dengan serat resam diperoleh hasil diantaranya: kekuatan tarik maksimal sebesar 19,022 MPa, regangannya $1,138 \%$, modulus elastisitasnya 2015,24 Mpa, tegangan lentur 58,735 MPa, modulus lenturnya $4221,349 \mathrm{MPa}$ dan tegangan impactnya $132 \mathrm{~kJ} / \mathrm{m}^{2}$. Hasil penelitian ini menunjukkan bahwa uji flexural dan uji impact sudah memenuhi standar plastic yang digunakan dashboard mobil, sedangkan uji tarik belum memenuhi standar plastik yang digunakan dashboard mobil, tetapi hasil penelitian ini masih bisa ditingkatkan untuk mencapai standar plastik ABS High Impact atau melebihi nilai plastik tersebut dengan cara menaikkan nilai ukuran panjang serat resam, hal ini terlihat dari adanya kenaikan nilai uji tarik secara kontinyu mulai dari $3 \mathrm{~mm}, 10 \mathrm{~mm}$ sampai 20mm [10].

Dalam penelitian yang sudah dilakukan oleh peneliti lain bahwa serat alam bisa ditingkatkan kemampuannya dengan perlakuan bahan kimia seperti $\mathrm{NaOH}$. Hal ini sangatlah berguna sekali untuk meningkatkan kualitas penelitian serat resam yang dilakukan oleh penulis. Oleh karena itu untuk mencapai pemanfaatan yang lebih luas lagi perlu dilakukan penelitian tersebut. Penelitian yang dilakukan ini untuk mendapatkan kekuatan tarik, kekuatan flexure dan kekuatan impact komposit serat resam yang sudah mendapat perlakuan $\mathrm{NaOH}$ sehingga bisa digunakan sebagai bahan dashboard kendaraan mobil.

\section{METODE PENELITIAN}

Untuk proses penelitian "Peningkatan kualitas serat resam untuk bahan komposit sebagai bahan pembuatan komponen kendaraan bermotor", Metode penelitian yang digunakan adalah metode eksperimental. Tahapan proses yang dilakukan dalam penelitian ini, yaitu:

1. Pembuatan sampel uji;

2. Pengujian mekanik;

3. Analisis data.

\section{A. Tahap pertama}

Pada tahap awal ini pembuatan sampel uji komposit serat resam dan polyester. Langkah yang dilakukan untuk pembuatan sampel ini adalah:

(1)Mempersiapkan serat resam dengan berbagai ukuran panjang;

(2)Membuat cetakan;

(3)Membuat benda uji dengan berbagai variasi ukuran serat beserta prosentasenya dan prosentase curing agent.

(4)Persiapan sampel uji sesuai standar (ASTM D 638 untuk uji tarik, ASTM D 790 untuk flexure dan ISO 179 untuk uji impact).

Pada penelitian ini, bahan-bahan dan material yang digunakan:

1. Serat resam;

2. Larutan $5 \% \mathrm{NaOH}$; 
3. Resin unsaturated polyester dengan merk Yukalac 157 BQTN-EX sebagai matriks;

4. Metil etil keton peroksida (MEKPo) sebagai hardener/curing agent ;

5. Wax glasses untuk mencegah menempelnya resin ke permukaan cetakan.

Benda uji dibuat dengan cara mencampurkan langsung serat resam, resin dan curing agent, sebelumnya serat resam sudah dibuat dalam beberapa variasi serat dalam ukuran panjang $20 \mathrm{~mm}$, 40mm, dan $60 \mathrm{~mm}$. Setelah itu variasi ukuran panjang serat direndam dalam larutan $5 \% \mathrm{NaOH}$ yang divariasikan waktu rendamnya 10 menit, 2 jam dan 4 jam. Kemudian serat ditimbang sesuai dengan prosentase yang diinginkan, parameter prosentase berat resam tersebut adalah $25 \%$, $30 \%$, dan $35 \%$ terhadap komposit dan $1,5 \%$ curing agent. Untuk ukuran benda uji maka akan dibuat berdasarkan standar uji tarik (ASTM D 638), standar uji flexure (ASTM D 790), dan standar uji impact (ISO-179).

\section{B. Tahap kedua}

Tahap kedua untuk mendapat karakteristik mekanik komposit berupa: kekuatan tarik, modulus elastisitas, regangan, tegangan lentur, modulus lentur dan tegangan impact.

\section{Tahap ketiga}

Pada tahap ini melakukan pengumpulan data dari hasil pengujian dan selanjutnya dari data yang sudah dikumpulkan, dilakukan analisis data untuk mengetahui karakteristik yang ditemukan pada komposit hasil penelitian ini.

\section{HASIL DAN PEMBAHASAN}

Jumlah benda eksperimen untuk setiap pengujian adalah 9 variasi, dengan setiap variasi dilakukan 2 kali replikasi sehingga jumlah benda eksperimen yang dibuat untuk setiap proses pengujian seluruhnya adalah 18 buah. Hasil pengujian benda uji di laboratorium material Politeknik Manufaktur Negeri Bangka Belitung dengan berbagai variasi serat resam, variasi larutan $\mathrm{NaOH} 5 \%$, resin dan curing agent dapat dilihat di bawah ini.
Hasil pengujian tarik

Hasil pengujian tarik dengan menggunakan standar ASTM D-638 terdiri dari kekuatan tarik (Gambar 2) dan modulus elastisitas (Gambar 3).

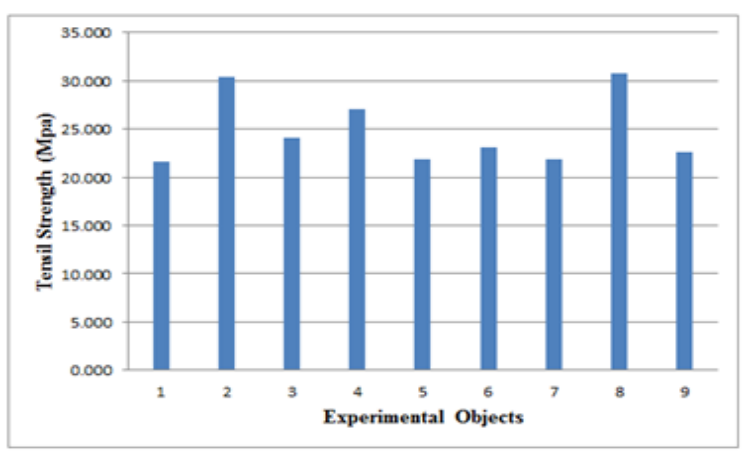

Gambar 2. Kekuatan tarik

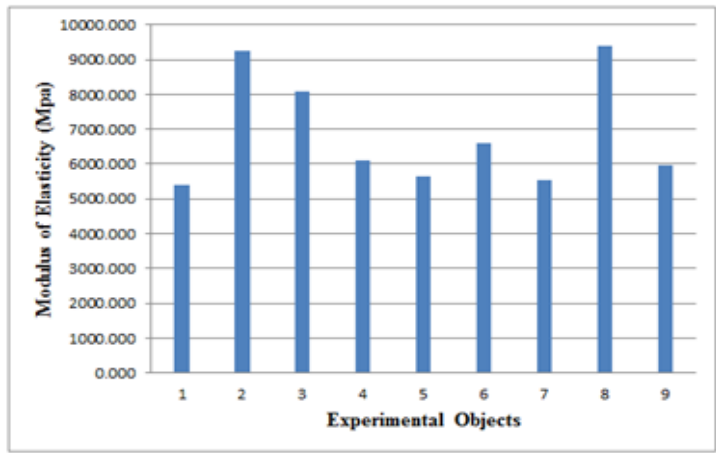

Gambar 3. Modulus elastisitas

Dari grafik yang ditampilkan pada Gambar 2 dan gambar 3 ini dapat dianalisis beberapa hal diantaranya adalah:

- Nilai maksimum kekuatan tarik adalah $30,750 \mathrm{MPa}$ dan modulus elastisitasnya 9400,00 Mpa.

- Kekuatan tarik dan dari dashboard mobil yang memiliki jenis bahan plastik ABS High Impact adalah sebesar 20-40 Mpa, sedangkan Nilai modulus elastisitas antara 1-2,5 Gpa (1000-2500 Mpa), sehingga penelitian ini sudah memenuhi standar.

Hasil pengujian flexure dan Impact.

Hasil pengujian flexure dengan menggunakan standar ASTM D-790 mendapatkan tegangan lentur (Gambar 4) dan standar ISO-179 untuk mendapatkan tegangan impact (Gambar 5). 


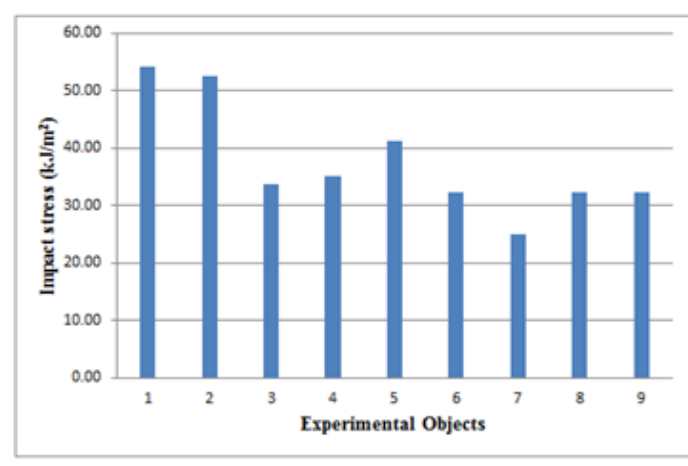

Gambar 4. Tegangan Flexure

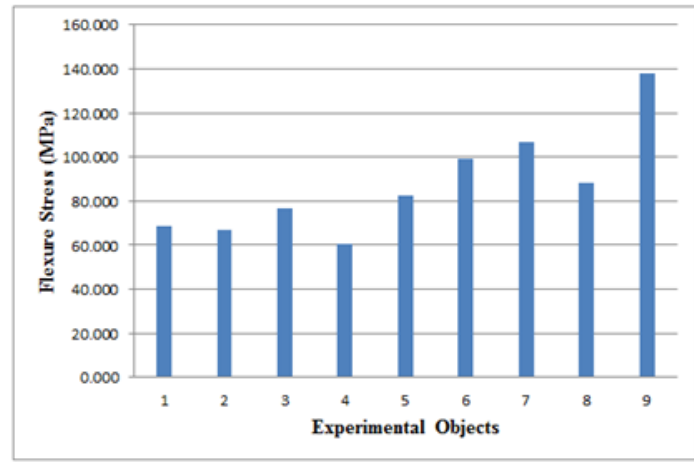

Gambar 5. Tegangan Impact

Dari grafik yang ditampilkan pada Gambar 4 dan Gambar 5 ini dapat dianalisis beberapa hal diantaranya adalah:

- Nilai maksimum Tegangan lentur adalah $138 \mathrm{MPa}$ dan tegangan impact adalah $54,14 \mathrm{~kJ} / \mathrm{m}^{2}$.

- Nilai tegangan lentur dari dashboard mobil yang memiliki jenis bahan plastik ABS High Impact adalah 37-76 MPa sedangkan Untuk kekuatan impact dari dashboard mobil yang memiliki jenis bahan plastik ABS adalah sebesar 13,48 $\mathrm{kJ} / \mathrm{m}^{2}$ Sehingga kedua tegangan dari penelitian ini sudah memenuhi standar.

\section{KESIMPULAN}

Dari hasil proses pengujian tarik, flexure dan impact diperoleh hasil maksimum untuk tegangan tarik 30,750 Mpa, modulus elastisitas $9400 \mathrm{Mpa}$, tegangan flexure/lentur $138 \mathrm{Mpa}$, dan tegangan impact $54,14 \mathrm{~kJ} / \mathrm{m}^{2}$. Semua hasil proses pengujian ini bila dibandingkan dengan standar plastik yang digunakan untuk dashboard mobil ternyata sudah memenuhi standar, sehingga bisa dijadikan salah satu bahan komposit baru untuk dashboard mobil.
DAFTAR PUSTAKA

[1]. Neng Sri Suharty, 2007, Rekayasa polimer menggantikan bahan tradisional, Pidato Pengukuhan guru besar kimiaUniversitas Sebelas Maret.

[2]. Basuki Widodo, 2008, Analisa sifat mekanik komposit epoksi dengan penguat serat pohon aren (ijuk) model lamina berorientasi sudut acak (random), Jurnal teknologi technoscientia.

[3]. Muh Amin dan Samsudi R, 2010, Pemanfaatan limbah serat sabut kelapa sebagai bahan Pembuat helm pengendara kendaraan roda dua, Prosiding nasional unimus.

[4]. Rajesh Ghosh, A. Rama Krishna , G. Reena , dan Bh.Lakshmipathi Raju, 2011, Effect of fibre volume fraction on the tensile strength of Banana fibre reinforced vinyl ester resin composite, International journal of advanced engineering sciences and technologies.

[5]. Lawrence T. Drzal, 2007, Sustainable Bio-Based Structural Material: opportunities and challenges, Michigan State University.

[6]. George J., Janardhan R., Anand, J.S., Bhagawan S.S., dan Thomas S. 1996. Melt Rheological Behavior Of Short Pineapple Fibre Reinforced Low Density Polyethylene Composites, Journal Of Polymer, Volume 37, No. 24, Gret Britain.

[7]. Jefferjee B., Heyleys, dan Zylyon. 2003. Composite Aplication using Coir Fibres in Sri Lanka, Final report of fast track project from Common Fun for Commodities, Delft University of Technology, Netherlands.

[8]. Prasad S. V., Pavithran, C., dan Rohatgi, P. K. 1983. Alkali treatment for coir fibres for coir-polyester composites, Research regional laboratory, India, pp. 1443-1454.

[9]. Nayak S. K., Tripahy S.S., Rout, J., dan Mohanty, A.K. 2000. Coir-Polyester Composite: Effect on fibre surface treatment on mechanical properties of composite, International Plastics Engineering and Technology, Vol.04, pp.79-86. 
[10]. Herwandi, Sugianto, Somawardi, dan Muhammad Subhan, 2013. Pengaruh Variasi Volume Serat Resam Terhadap Kekuatan Tarik dan Impact Komposit pada Matriks Polyester sebagai Bahan Pembuatan Dashboard Mobil, Prosiding Seminar Nasional Mesin dan Industri (SNMI VIII) 2013 di Universitas Tarumanagara. 